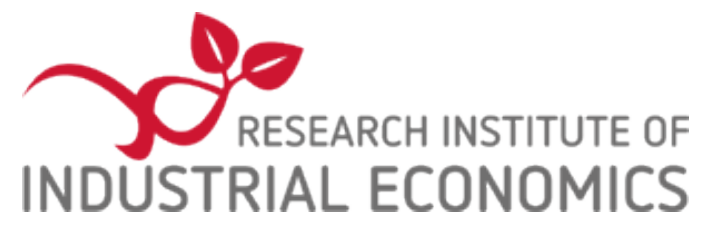

IFN Working Paper No. 1191, 2017

\title{
Cournot Competition in Wholesale Electricity Markets: The Nordic Power Exchange, Nord Pool
}

Erik Lundin and Thomas Tangerås 


\title{
Cournot Competition in Wholesale Electricity Markets: The Nordic Power Exchange, Nord Pool*
}

\author{
Erik Lundin ${ }^{\dagger}$ and Thomas P. Tangerås ${ }^{\ddagger}$
}

November 20, 2017

\begin{abstract}
Horizontal shifts in bid curves observed in wholesale electricity markets are consistent with Cournot competition. Quantity competition reduces the informational requirements associated with evaluating market performance because the markups of all producers then depend on the same inverse residual demand curve instead of one for each firm. We apply the model to the day-ahead market of the Nordic power exchange, Nord Pool, for the years 2011-2013. Results suggest that mark-ups were 8-11 percent. We find some support for the hypothesis that the division of Sweden into price areas in 2011 increased the exercise of market power.

Key words: Cournot competition, market design, market performance, Nord Pool, Walrasian auction, wholesale electricity market
\end{abstract}

JEL: D22, D43, D44, D4

${ }^{*}$ We would like to thank Pär Holmberg, Johan Stennek, Frank A. Wolak, participants at the 9th Swedish Workshop on Competition and Public Procurement Research (2017) in Stockholm and at the IAEE Eurasian Conference (2017) in Zagreb for discussions and helpful comments. This research was conducted within the framework of the IFN research program "The Economics of Electricity Markets". The authors gratefully acknowledge financial support from Jan Wallanders och Tom Hedelius Stiftelse, the Swedish Competition Authority and the Swedish Energy Agency.

${ }^{\dagger}$ Research Institute of Industrial Economics (IFN). Email: erik.lundin@ifn.se. Website: www.eriklundin.org.

${ }^{\ddagger}$ Research Institute of Industrial Economics (IFN). Affiliate researcher, Energy Policy Research Group (EPRG) University of Cambridge. Visiting scholar, Stanford University. E-mail: thomas.tangeras@ifn.se. Website: www.ifn.se/thomast 


\section{Introduction}

The performance of electricity markets has been a major topic among market monitors and in empirical industrial organization since deregulation of electricity markets began in the 1990s. One reason is the high degree of ownership concentration of generation capacity, which together with a highly price inelastic demand, creates opportunities for exploiting market power. Another reason is the rich set of available data that have created opportunities to estimate less parameterized models than what is usually possible in other markets, where researchers often have relied on the conjectural variations approach developed by Bresnahan (1982) and Lau (1982).

The most notable feature of liberalized electricity markets is that wholesale markets typically are organized as Walrasian auctions: Producers, retailers and large industrial consumers submit price-dependent offers or bids to a centralized clearing house, often a power exchange, aggregating these offers and bids to obtain a market-clearing price. As a consequence, supply and demand curves can be separately observed rather than estimated by means of simultaneous equation methods. It is even possible to calculate the residual demand functions facing individual firms. The slope of the residual demand function then measures that firm's ability to influence the wholesale price, i.e. the individual firm-level market power.

The practical applicability of this approach is limited by the fact that researchers often do not have access to bid data at the firm level. However, we show in Section 2 of this paper that one can simplify the analysis if firms with market power bid their quantities inelastically into the wholesale market at a low price. Under such Cournot competition, firms' market power depends on the slope of the aggregate residual demand curve instead of individual demand curves. This curve can be computed on the basis of aggregate bid data that more often are publicly available. In our theoretical model, exogenous shifts in demand affect the total Cournot output via two additively separable channels. The first is the direct effect of a price change. The second effect only occurs under imperfect competition and works through a change in the slope of the inverse residual demand curve. These theoretical results can form the basis of empirical analysis of wholesale electricity markets characterized by Cournot competition.

We illustrate in Section 3 the usefulness of the approach by an examination of data from the Nordic power exchange, Nord Pool, during 2011-13. This company operates the most important platform for trading wholesale electricity in the Nordic market, the day-ahead market Elspot. Our first observation is that the majority of supply bid variation on Elspot stems from horizontal shifts in the supply curves across hours, consistent with large firms competing in quantities. We then regress this "Cournot output" on prices and residual demand slopes using an instrumental variables approach. In particular, the slope of the inverse residual demand function is significantly negatively correlated with Cournot output, as would be the case if firms exercised market power. This statistical relationship is inconsistent with perfect competition during peak hours, which leads us to reject the null hypothesis that Elspot was perfectly competitive in the sample period. Based upon the coefficient estimates, we compute implied price-cost margins in the range of 8 to 
11 percent. We also explore an exogenous change in market design that occurred in November 2011. Sweden was then divided into four price areas, whereas it had previously constituted a single price area. Our estimates are consistent with an increase in the exercise of market power subsequent to the reform. We round off the paper by some concluding remarks in Section 4 .

The identification of imperfect competition depends here on exogenous variation in the curvature of the inverse residual demand curve, but does not require the demand curve to rotate. We also acknowledge that the residual demand curve typically is convex during peak hours, when we expect market power to be more accentuated. Such convexity yields a positive correlation between price and (the absolute value of) the slope of the inverse residual demand curve independent of whether there is imperfect or perfect competition. We therefore use quantity instead of price as our dependent variable, to avoid false indications of the exercise of market power.

We believe our approach could be fruitfully applied to other wholesale electricity markets as well. Non-individual bid data are available for instance for Austria, France, Germany, and Switzerland. Visual inspection of bid data from Germany suggests that horizontal supply shifts are important sources of supply variation even here, as depicted in Figure B.1. Consistent with this observation, Willems et al. (2009) find a Cournot model to explain short term price variations in the German market just as well as a more complex Supply Function Equilibrium model. It also appears that this bidding behavior is not restricted to the European markets. An example of horizontal supply shifts in the US Midwest market is depicted in Figure B.2 adapted from Mercadal (2016).

Related literature This paper is among the first to take advantage of the detailed bid data that has become available in recent years, to assess market performance in the Nordic electricity market. Lundin (2016) uses shifts in the aggregate supply curve to estimate strategic aspects of maintenance scheduling among Swedish nuclear power plants. Tangerås and Mauritzen (2017) exploit differences between the day-ahead and intra-day markets to analyze market power. That method relies explicitly on the inter-temporality of hydro power markets and cannot be generalized to thermal markets, contrary to the method in the present paper.

Earlier studies, such as Bask et al. (2011), typically are applications of the Bresnahan-Lau model. Damsgaard (2007) and Kauppi and Liski (2008) are exceptions. They build simulation models to account for hydro production. More recently, Fogelberg and Lazarczyk (2014) analyze market power by means of announced production failures. These papers find evidence of market power to varying degree.

Bidding data at the firm level are available in some countries. Notably, McRae and Wolak (2014) (New Zealand) and Wolak (2003) (California) demonstrate that firms submit higher-priced bids when residual demand is less price elastic. Well-known studies of the British market are Green and Newbery (1992), Wolfram (1999), Wolak and Patrick (2001) and Sweeting (2007), all of whom find evidence of market power. Fabra and Toro (2005) find indications of periods with both collusion and price wars in the Spanish market. Ito and Reguant (2016) show that large 
firms exert market power by shifting output between the day-ahead and intra-day markets.

\section{Theoretical analysis}

The wholesale market The demand $X(\hat{p}, \sigma)$ for electricity is a non-increasing function of the wholesale price $\hat{p}$ of electricity and an increasing function of the demand parameter $\sigma$. We treat in this section $\sigma$ as a scalar, but it is relevant to think of it as a vector containing temperature, seasonal variation, and so forth. A subset $K=\{1, \ldots, k\}$ of the $n \geq k$ generation owners possess market power. Each firm $i \in K$ bids its production $\tilde{q}_{i}$ inelastically into the wholesale market. Let $M C^{i}\left(\tilde{q}_{i}, \gamma_{i}\right)$ be the non-decreasing marginal production cost of firm $i \in K$. All remaining firms $i \notin K$ act as a competitive fringe, bidding in the residual production $\tilde{q}_{r}$ at strictly increasing marginal production cost $M C^{r}\left(\tilde{q}_{r}, \gamma_{r}\right)$. The $k+1$ vector of parameters $\gamma=\left(\gamma_{1}, \cdots, \gamma_{k}, \gamma_{r}\right)^{\prime}$ is a set of firm-specific cost shifters of the marginal cost functions. Let the demand function and all marginal cost functions be twice continuously differentiable in their respective arguments.

The market-clearing condition

$$
P=M C^{r}\left(X(P, \sigma)-\tilde{Q}, \gamma_{r}\right)
$$

returns the inverse residual demand $\tilde{p}=P\left(\tilde{Q}, \sigma, \gamma_{r}\right)$ facing the $k$ Cournot producers, as a function of the total Cournot quantity $\tilde{Q}=\sum_{i=1}^{k} \tilde{q}_{i}$ and the two parameters $\sigma$ and $\gamma_{r}$.

Comparative statics of demand The inverse residual demand curve is strictly decreasing in Cournot output (subscripts on functional operators denote partial derivatives throughout),

$$
P_{Q}\left(\tilde{Q}, \sigma, \gamma_{r}\right)=\frac{-M C_{q}^{r}\left(X(\tilde{p}, \sigma)-\tilde{Q}, \gamma_{r}\right)}{1-M C_{q}^{r}\left(X(\tilde{p}, \sigma)-\tilde{Q}, \gamma_{r}\right) X_{p}(\tilde{p}, \sigma)}<0,
$$

whereas it can be locally convex or concave:

$$
\begin{aligned}
\frac{P_{Q Q}\left(\tilde{Q}, \sigma, \gamma_{r}\right)}{-P_{Q}\left(\tilde{Q}, \sigma, \gamma_{r}\right)} & =\frac{M C_{q q}^{r}\left(X(\tilde{p}, \sigma)-\tilde{Q}, \gamma_{r}\right)}{M C_{q}^{r}\left(X(\tilde{p}, \sigma)-\tilde{Q}, \gamma_{r}\right)}\left[1-X_{p}(\tilde{p}, \sigma) P_{Q}\left(\tilde{Q}, \sigma, \gamma_{r}\right)\right]^{2} \\
& +P_{Q}^{2}\left(\tilde{Q}, \sigma, \gamma_{r}\right) X_{p p}(\tilde{p}, \sigma) .
\end{aligned}
$$

In the relevant case of price inelastic total demand, so that $X_{p p}(\cdot, \sigma)$ is close to zero, $P_{Q Q}\left(\tilde{Q}, \sigma, \gamma_{r}\right) \gtrless$ 0 depending on whether the marginal cost function $M C^{r}\left(\cdot, \gamma_{r}\right)$ of the competitive fringe is convex or concave. The price effect of a marginal exogenous increase in demand is proportional to the slope of the inverse demand curve:

$$
P_{\sigma}\left(\tilde{Q}, \sigma, \gamma_{r}\right)=-P_{Q}\left(\tilde{Q}, \sigma, \gamma_{r}\right) X_{\sigma}(\tilde{p}, \sigma)>0
$$


and the marginal effect on the slope of the demand curve is related to its curvature:

$$
P_{Q \sigma}\left(\tilde{Q}, \sigma, \gamma_{r}\right)=-P_{Q Q}\left(\tilde{Q}, \sigma, \gamma_{r}\right) X_{\sigma}(\tilde{p}, \sigma)-P_{Q}^{2}\left(\tilde{Q}, \sigma, \gamma_{r}\right) X_{p \sigma}(\tilde{p}, \sigma)
$$

A plausible representation of demand is $X(\hat{p}, \sigma)=\sigma+Y(\hat{p})$, where $Y(\bar{p})=0$ at the bid cap $\bar{p}$, and $Y_{p}(\hat{p}) \leq 0$ for all $p>\bar{p}$. The parameter $\sigma$ then represents demand at the bid cap. In this case, $X_{\sigma}(\hat{p}, \sigma)=1$ and $X_{p \sigma}(\hat{p}, \sigma)=0$, which implies

$$
P_{\sigma}\left(\tilde{Q}, \sigma, \gamma_{r}\right)=\left|P_{Q}\left(\tilde{Q}, \sigma, \gamma_{r}\right)\right| \text { and } P_{Q \sigma}\left(\tilde{Q}, \sigma, \gamma_{r}\right)=-P_{Q Q}\left(\tilde{Q}, \sigma, \gamma_{r}\right)
$$

All demand variation here occurs as horizontal shifts in the demand curve. In particular, there is no exogenous variation that causes total demand to rotate around the price.

Firm Optimization Firm $i \in K$ enters the production stage with contractual obligations for $f_{i} \mathrm{MWh}$ electricity. This is a composite contract containing forwards and futures of different maturities, bilateral contracts with large industrial customers and direct deliveries to households through vertical integration with electricity retailers, all indexed against the electricity wholesale price $\hat{p}$. Let $g_{i}$ be the (sunk) price of this composite contract.

Cournot producer $i \in K$ maximizes

$$
\alpha_{i} P\left(\tilde{Q}, \sigma, \gamma_{r}\right) \tilde{q}_{i}-\int_{0}^{\tilde{q}_{i}} M C^{i}\left(z, \gamma_{i}\right) d z+\alpha_{i}\left(g_{i}-P\left(\tilde{Q}, \sigma, \gamma_{r}\right)\right) f_{i}+\left(1-\alpha_{i}\right) \int_{0}^{\tilde{Q}} P\left(Z, \sigma, \gamma_{r}\right) d Z
$$

over $\tilde{q}_{i}$ taking the production of all firms $i \notin K$ as given. The parameter $\alpha_{i} \in(0,1]$ represents a trade-off between social welfare and profit in producer $i$ 's objective function. The firm is a pure profit maximizer if $\alpha_{i}=1$, whereas it behaves closely to that of a central planner if $\alpha_{i}$ is close to zero. The parameter $\alpha_{i}$ could vary across firms, for instance depending on whether producers are privately owned or (partially) state-owned companies. Such mixed ownership constellations are common in electricity markets.

Equilibrium The equilibrium condition of firm $i \in K$ reads

$$
p-m c_{i}=\alpha_{i}\left(q_{i}-f_{i}\right)\left|P_{Q}\right|
$$

where $p=P\left(Q, \sigma, \gamma_{r}\right)$ is the wholesale price in Cournot equilibrium and $Q=Q(\sigma, \gamma)$ the total output of the $k$ firms with market power, $m c_{i}=M C^{i}\left(q_{i}, \gamma_{i}\right)$ is the equilibrium marginal cost of firm $i \in K$ and $q_{i}$ its equilibrium production. $P_{Q}=P_{Q}\left(Q, \sigma, \gamma_{r}\right)$ is the slope of the inverse residual demand curve evaluated at the equilibrium output. For future reference, we let $P_{Q Q}$, $P_{\sigma}, P_{Q \sigma}$ and $M C_{q}^{i}$ be similarly defined.

Condition (2) offers three explanations for why a firm with market power would nevertheless behave competitively. The first is the intensity of competition. A firm will have a small price- 
cost margin if the price is unresponsive to marginal changes in output, i.e. $\left|P_{Q}\right|$ is close to zero. The second reason is forward contracting and/or vertical integration. A firm has little to gain from increasing the price above the competitive level if it has already sold most of its output up front, i.e. $\left|q_{i}-f_{i}\right|$ is small. The third explanation has to do with organizational design. A firm will exercise market power only to a small extent if it is set up to take consumer surplus into account, i.e. $\alpha_{i}$ is small.

The intensity of competition in (2) is defined in terms of the absolute value $\left|P_{Q}\right|$ of the slope of the aggregate residual inverse demand curve, unlike in other strategic settings where the residual demand curves at the individual level influence the equilibrium markups. This feature allows us to sum up (2) across all Cournot firms to get an equilibrium condition

$$
p-m c=\theta\left|P_{Q}\right|
$$

that is independent of firm-specific factors. ${ }^{1}$ The left-hand side of (3) is the markup of the price over the average marginal cost $m c=\frac{1}{k} \sum_{i=1}^{k} m c_{i}$ of the $k$ Cournot producers. The parameter $\theta$ on the right-hand side of $(3)$ is the average net contract coverage

$$
\theta=\frac{1}{k} \sum_{i=1}^{k} \alpha_{i}\left(q_{i}-f_{i}\right)
$$

of the $k$ firms with market power, weighted by the organizational parameters.

It will be convenient to base the empirical analysis on a different formulation than (3). It is better to use quantities instead of prices as the dependent variable, as we explain later. Assume for now that all Cournot producers $i \in K$ have linear marginal cost functions, $M C^{i}\left(\tilde{q}_{i}, \gamma_{i}\right)=\gamma_{i}+c_{i} \tilde{q}_{i}$. We can then rewrite equilibrium condition (2) as

$$
\gamma_{i}+c_{i} q_{i}=p-\left|P_{Q}\right| \alpha_{i}\left(q_{i}-f_{i}\right)
$$

Move $\gamma_{i}$ to the right-hand side, divide through by $c_{i}$, and sum up over all $k$ firms to get:

$$
Q=-\sum_{i=1}^{k} \frac{\gamma_{i}}{c_{i}}+p \sum_{i=1}^{k} \frac{1}{c_{i}}-\left|P_{Q}\right| \sum_{i=1}^{k} \alpha_{i} \frac{q_{i}-f_{i}}{c_{i}}
$$

Any exogenous change in demand that drives up the equilibrium price $p$ or reduces the slope $\left|P_{Q}\right|$ of the inverse residual demand curve, tends to increase the total Cournot output $Q$ on the left-hand side of (4). There is also an indirect effect effect through $q_{i}$, but this is dominated by the direct effect under an appropriate regularity condition (the proof is in Appendix A):

Proposition 1. The effect of a marginal increase in demand on the total production $Q$ of the $k$

\footnotetext{
${ }^{1}$ The equilibrium condition (2) depends the organizational parameter $\alpha_{i}$ and the net contract position $q_{i}-f_{i}$, both of which are firm-specific. These are sometimes observable, one can control for them, or they can be estimated. Empirical results reported by McRae and Wolak (2014) can be interpreted in terms of estimates of $\alpha_{i}$ for the largest firms in the New Zealand wholesale electricity market. Unfortunately, researchers very seldom have access to such detailed data and therefore must rely on aggregate conditions such as (3) for estimation.
} 
firms with market power equals

$$
Q_{\sigma}=P_{\sigma} H+P_{Q \sigma} H \frac{\sum_{i=1}^{k} \frac{\alpha_{i}\left(q_{i}-f_{i}\right)}{M C_{q}^{i}-\alpha_{i} P_{Q}}}{\sum_{i=1}^{k} \frac{1}{M C_{q}^{i}-\alpha_{i} P_{Q}}}
$$

in Cournot equilibrium, where

$$
H=\frac{\sum_{i=1}^{k} \frac{1}{M C_{q}^{i}-\alpha_{i} P_{Q}}}{1-\sum_{i=1}^{k} \frac{P_{Q}+\alpha_{i}\left(q_{i}-f_{i}\right) P_{Q Q}}{M C_{q}^{i}-\alpha_{i} P_{Q}}}
$$

is strictly positive if the equilibrium is stable.

The proposition shows that the marginal demand effect generally (not only for the linear specification of marginal costs) can be divided into two additively separate parts. The effect on the price resulting from an increase in demand makes it more profitable to increase Cournot production. This is the first marginal effect in (5). However, the change in demand affects also the slope of the inverse demand curve facing firms with market power. Any change in demand that renders the price of electricity more sensitive to changes in Cournot output $\left(P_{Q \sigma}<0\right)$ causes firms that exercise seller power to withhold output from the market. This is the second marginal effect in (5). In principle, the second effect can dominate the first, in which case firms with market power produce less when demand is higher. In particular, the marginal slope effect $P_{Q \sigma}$ matters if and only if firms exercise market power. It vanishes under perfect competition, i.e. if $\alpha_{i}\left(q_{i}-f_{i}\right)=0$ for all firms $i \in K$.

Notice also that if demand is of the form $X(\hat{p}, \sigma)=\sigma+Y(\hat{p})$, then $P_{\sigma}=\left|P_{Q}\right|$ and $P_{Q \sigma}=-P_{Q Q}$, and we can use the slope and curvature of the inverse residual demand curve evaluated at the equilibrium to estimate market performance.

\section{Empirical analysis: The Nordic wholesale electricity market}

\subsection{Institutional background}

The national electricity markets in the Nordic countries were deregulated one after the other during the 1990s and integrated to create a common wholesale electricity market for Denmark, Finland, Norway and Sweden. This Nordic market was later expanded to include Estonia, Latvia, and Lithuania. Recently, it has been coupled also with continental Europe.

The main trading platform for physical energy is the day-ahead market, Elspot, operated by the Nordic power exchange, Nord Pool. Elspot trades more than 80 percent of all electricity produced in the region, and is the market we analyze in this paper. It works as follows.

Every day at noon, market participants submit bids to Nord Pool for each of the 24 hours of the 
Table 1: Production mix in the Nordic market

\begin{tabular}{lc}
\hline Production type & Percentage of production \\
\hline Hydro & 49 \\
Thermal (non-nuclear) & 19 \\
Nuclear & 27 \\
Wind & 5 \\
\hline Note: This table depicts market shares by energy \\
source for the Nordic market during 2011-2013.
\end{tabular}

following day. Each participant can submit hourly bids consisting of at most 62 quantity/price pairs up to a bid cap. ${ }^{2}$ Nord Pool then connects all quantity/price pairs by linear interpolation to create system hourly supply and demand curves. Participants have the possibility to submit block bids in addition to the above regular bids. A block bid differs from a regular bid in two respects. First, it is tied across two or more consecutive hours. Second, a block-bid is either accepted or rejected in full. Nord Pool applies an iterative algorithm to find a combination of block bids that maximizes total market surplus. The volume of accepted block bids and net exports (which mainly consist of trade with continental Europe) enter as one single inelastic bid in the computation of the hourly market clearing system price. ${ }^{3}$ The equilibrium price equals the system price if there are no network constraints in the system. But if the transmission capacities reported by the system operators are insufficient to handle the trade flows necessary to clear the market at the system price, then Nord Pool is obliged to recalculate the market. Elspot can then be partitioned into as much as 15 different price areas with local market clearing, the geographical borders of which are illustrated in Figure B.4. The clearing procedure applied by Nord Pool implies that the slope of the residual demand function facing any given firm is always well defined for every hour, unlike in many other electricity markets. The price area configuration itself may change over time. For instance, Sweden went from being one single price area, to having the four price areas depicted in the figure in November 2011.

The system price is the reference price for the main financial products. Thus, if a producer has sold a forward contract for $1 \mathrm{MWh}$ at a price of $10 \mathrm{EUR}$ and the day-ahead price is realized at 9 EUR/MWh, the producer receives apayment of 1 EUR from the buyer of the contract. Vertical integration, i.e., when a firm is active in both the wholesale and retail markets, has a similar effect, although retail contracts are physical rather than financial. Retail prices are unregulated in the Nordic region and often set as a markup over the mean day-ahead price for a certain period (usually 3 months or more). ${ }^{4}$

The production mix for the whole market is depicted in Table 1. The two major energy sources are

\footnotetext{
${ }^{2}$ The bid cap was $2000 \mathrm{EUR} / \mathrm{MWh}$ in our sample, but increased to $3000 \mathrm{EUR} / \mathrm{MWh}$ in 2015. Historically, prices have never risen to the level of the bid cap.

${ }^{3}$ On average, 5 and 1 percent respectively of the accepted sell- and buy volumes in the data are block bids. Net exports account for 6 percent of the total cleared volume.

${ }^{4}$ See Wolak (2007) for an empirical examination of the competitive effects of forward contracting in the Australian electricity market, and Bushnell et al. (2008) for the competitive effects of vertical integration in three electricity markets in the U.S.
} 
Table 2: Market shares of the largest firms

\begin{tabular}{lc}
\hline Firm & Percentage of production \\
\hline Vattenfall & 19 \\
Statkraft & 14 \\
Fortum & 12 \\
E.ON & 7 \\
\hline Note: Market shares of total Nordic pro- \\
duction for the largest firms 2011-2013.
\end{tabular}

hydro power (49 percent) located in Norway and Sweden and nuclear power (27 percent) located in Finland and Sweden. The market is fairly concentrated, with market shares displaying little annual variation during the sample period. The firm with the largest share of total production is the Swedish state-owned firm Vattenfall (19 percent), followed by the Norwegian state-owned Statkraft (14 percent). The third largest producer is Fortum (12 percent), which has the Finnish state as the majority owner, followed by the German private energy firm E.ON (7 percent).

\subsection{Data}

We have downloaded system supply and demand curves, net exports and the volumes of accepted block bids from the Nordpool FTP-server, along with hydro reservoir inflow data and prognosticated consumption for the sample period 2011-2013. ${ }^{5}$ Based upon this bid data we can exactly reproduce the final step of Nord Pool's clearing algorithm and replicate all hourly system prices in our sample. Figure 1 depicts an example of a supply and demand function. The hourly system supply and demand curves contain around 600 quantity/price pairs each. The demand function is highly inelastic, except at low prices. The supply elasticity varies more. Nuclear and hydro power provide base load production, and are usually supplied at low prices. As demand increases, more thermal production is dispatched and the supply curve becomes steeper. As a result, the supply elasticity is generally lower in peak than off-peak hours. The average price during peak hours $(8 \mathrm{am}-8 \mathrm{pm}$ ) is 30 percent higher than the average price during off-peak hours, which is comparable to the price difference in the winter compared to the summer.

Table 3 reports summary statistics. We define the Cournot quantity as any bid below 5 EUR/MWh. Since the daily system price exceeded 5 EUR/MWh for the entire sample, such bids will in practice always be accepted. The mean Cournot quantity is $24 \mathrm{GWh}$, accounting for two-thirds of the mean cleared market quantity. The (absolute ) slope of the residual demand function facing the Cournot players is 1.79 , meaning that a one GWh decrease in the Cournot quantity will result in a $1.79 \mathrm{EUR} / \mathrm{MWh}$ increase in the equilibrium price. The mean of the corresponding elasticity, $\left|P_{Q}\right| \frac{Q}{p}$ (where $Q$ is the Cournot quantity and $p$ is the equilibrium price), is 1.2. Since the slope distribution is highly skewed, with a few exceptionally large outliers, we remove the top one

\footnotetext{
${ }^{5}$ Access to the Nord Pool FTP-server is subject to a subscription fee. But most of data are also available freeof-charge for manual downloads at the Nord Pool downloads center (www.nordpoolspot.com/download-center/). Bid data at individual firm or area levels are currently not publicly available.
} 
Figure 1: System supply and demand

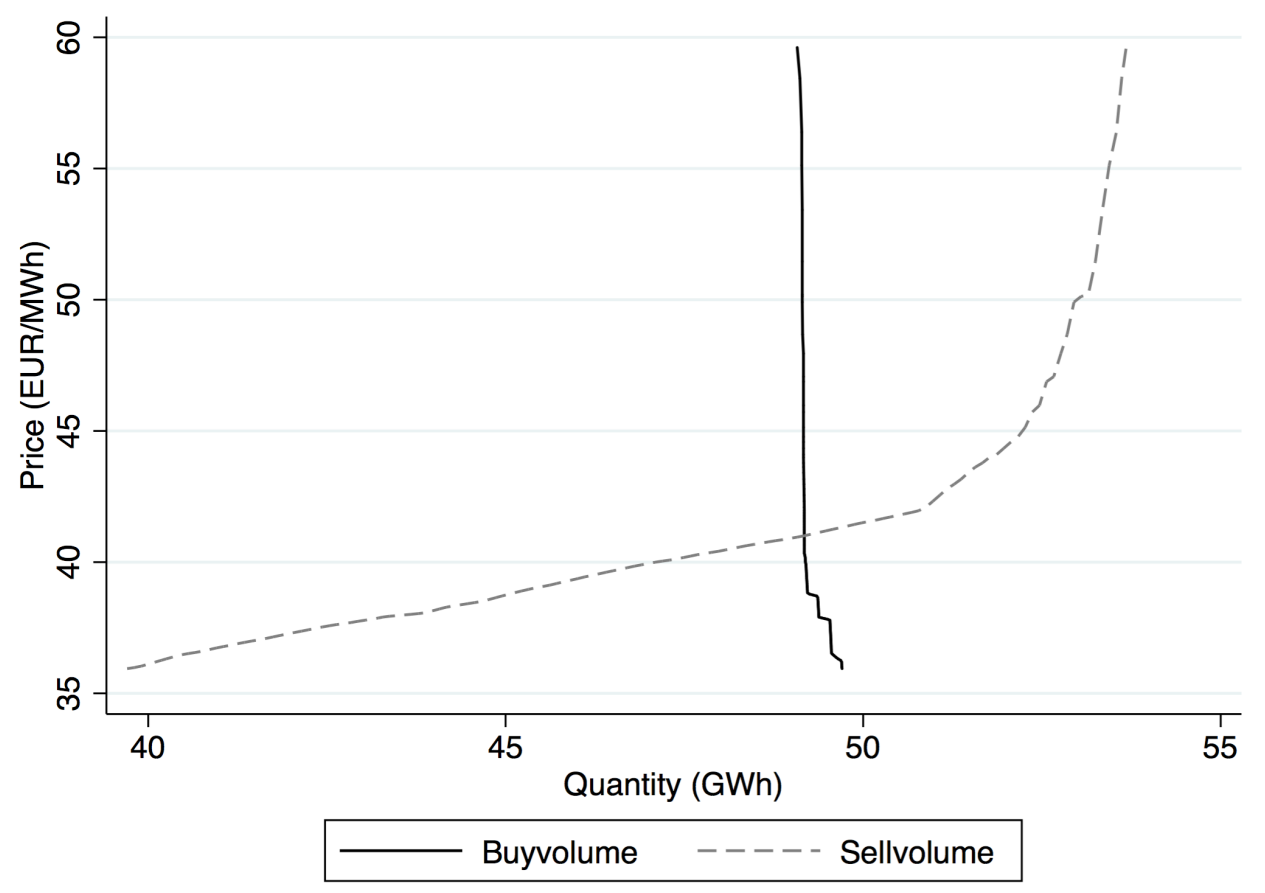

Note: Note: This figure depicts the system supply and demand functions on the Nordic day-ahead market during 2-3 pm, January 19, 2013.

Table 3: Summary statistics of data used in the main analysis

\begin{tabular}{lcccc}
\hline & & & & \\
& Mean & St.dev & Min & Max \\
\hline Cournot quantity & 24.31 & 3.38 & 15.92 & 33.54 \\
Equilibrium quantity & 34.27 & 6.98 & 19.58 & 57.34 \\
Demand forecast & 43.58 & 8.75 & 25.81 & 69.00 \\
Price & 38.45 & 13.73 & 1.40 & 224.88 \\
Slope & 1.79 & 3.13 & 0.25 & 35.40 \\
Reservoir inflow & 24.21 & 17.93 & 2.48 & 98.55 \\
Wind production in Sweden & 0.89 & 0.61 & 0.01 & 3.55 \\
Average temperature in Sweden & 7.20 & 8.22 & -20.55 & 26.43 \\
\hline
\end{tabular}

Note: Quantities and reservoir inflow are expressed in GWh, price in $\mathrm{EUR} / \mathrm{MWh}$, and temperature in Celsius. The consumption prognosis is larger than the equilibrium quantity since some of the electricity consumed is not traded on the day-ahead market. There is one observation per hour during 2011-2013, so $N=26304$. The exception is hydro inflow, which is only measured weekly. 
percent of the observations to ensure that these do not drive the results. This approach has also been used previously by e.g. Mercadal (2016). The demand forecast is 20 percent higher than the cleared day-ahead quantity, since some of the demand is traded through bilateral contracts. The demand forecast is published by the transmission system operators in each country at 11am the day before delivery, and bids can be submitted until noon.

Reservoir inflow, measured in GWh of potential electricity production, is about half of forecasted demand, consistent with the fact that hydro production represents about half of the production in the region. However, this variable is only available on a weekly basis. Wind output has been downloaded from the Swedish transmission system operator, and temperature has been provided by the Swedish Meteorological and Hydrological Institute. In contrast to regions with milder climate, air conditioning is not used in the Nordic region, so the relationship between temperature and demand is always negative.

Cournot bids are the main source of supply variation. Cournot bids account for the majority of accepted bids and also represent the main source of supply variation. This is illustrated in Figure 2, depicting a random number of system supply curves drawn from one single week. In fact, variations in the clearing price within any given week can be accurately replicated using static representations of the elastic portion of the supply functions, so that the only variation comes from Cournot bids. We construct these approximations by first fitting the supply functions in increments of $0.1 \mathrm{EUR} / \mathrm{MWh}$. After netting out the Cournot quantity associated with each bid, the mean weekly bid quantity is computed for each price level. In the last step, we fit the supply functions using a lowess smoothing filter. We interpret this supply function as the marginal cost curve of the competitive fringe for that week. Figure 3 depicts an example of such a supply function, together with the data points used to construct it. We then add the Cournot bids to each weekly supply curve and re-clear the market. The predicted prices are very close to the observed prices, with a median within-week correlation of 0.96 . Figure 4 displays the observed vs. the predicted prices for one week-of-sample.

Horizontal shifts have previously been found to be an important source of supply variation also in other wholesale electricity markets, for instance the Midwest market (Mercadal, 2016). Figure B.2 depicts a set of supply functions in that market for one firm that appear to be parallel shifts. Such variation could have other explanations than Cournot bidding. Hortaçsu and Puller (2008) find conditions under which variations in forward commitments induce shifts in the optimal supply function that leave the slope unchanged. In this case, the optimal supply schedule of firm $i$ can be written as $S_{i}\left(p, x_{i}\right)=\alpha_{i}\left(x_{i}\right)+\beta_{i}(p)$, where $x_{i}$ is the volume of forward commitments for firm $i$.

The financial products most common in the Nordic market are standardized forward contracts that clear against the monthly, quarterly, or yearly system price. However, due to a negligible liquidity in the weekly contracts (Nordreg, 2016) there is hardly any variation in the forward commitments within any given month, so variations in forward commitments cannot explain the majority of the variation in the supply shifts. Some of the Cournot bids come from intermittent 
Figure 2: Horizontal supply shifts on Nord Pool Elspot

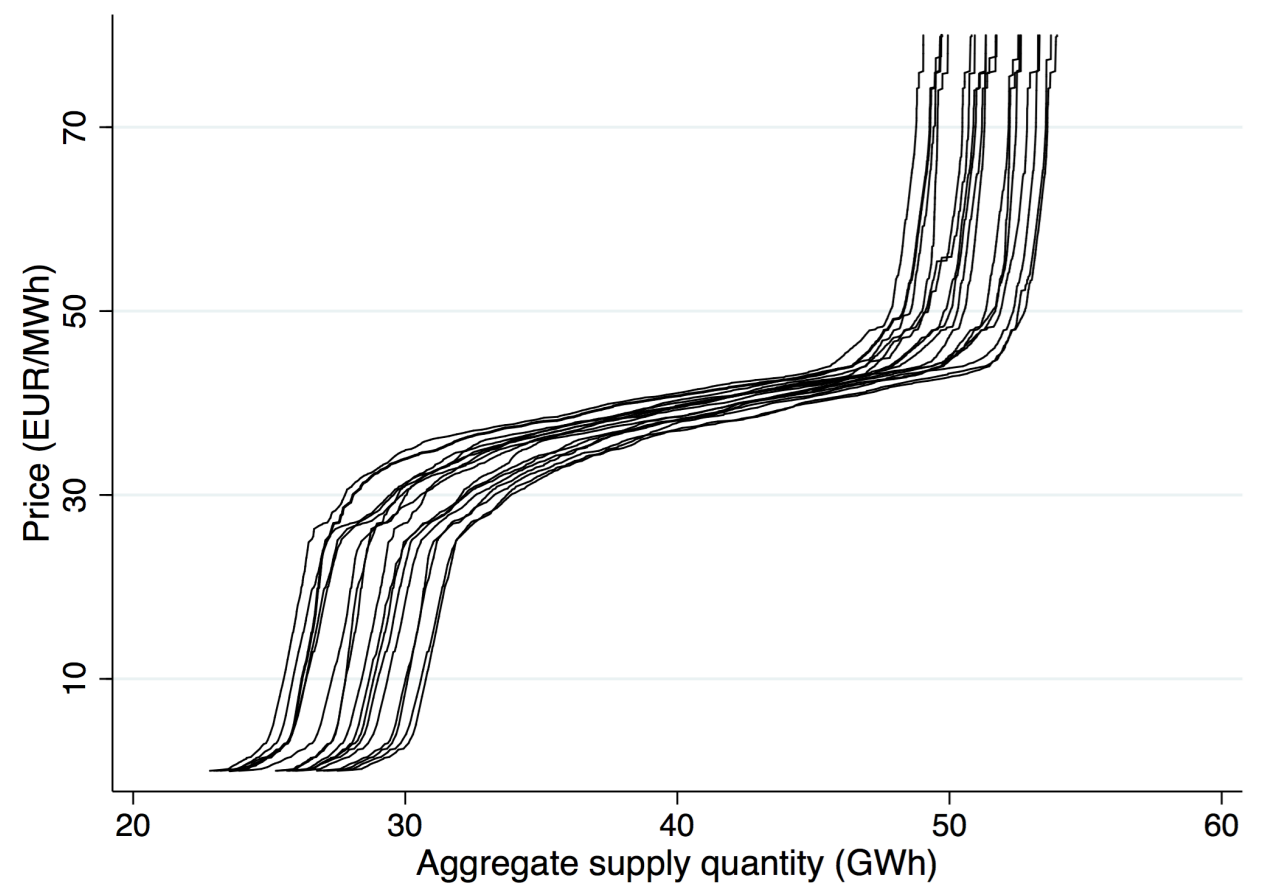

Note: The figure shows aggregate supply bids in the Nordic day-ahead market for a random set of hours March $1-7,2013$.

Figure 3: Constructing a representative supply function for one week

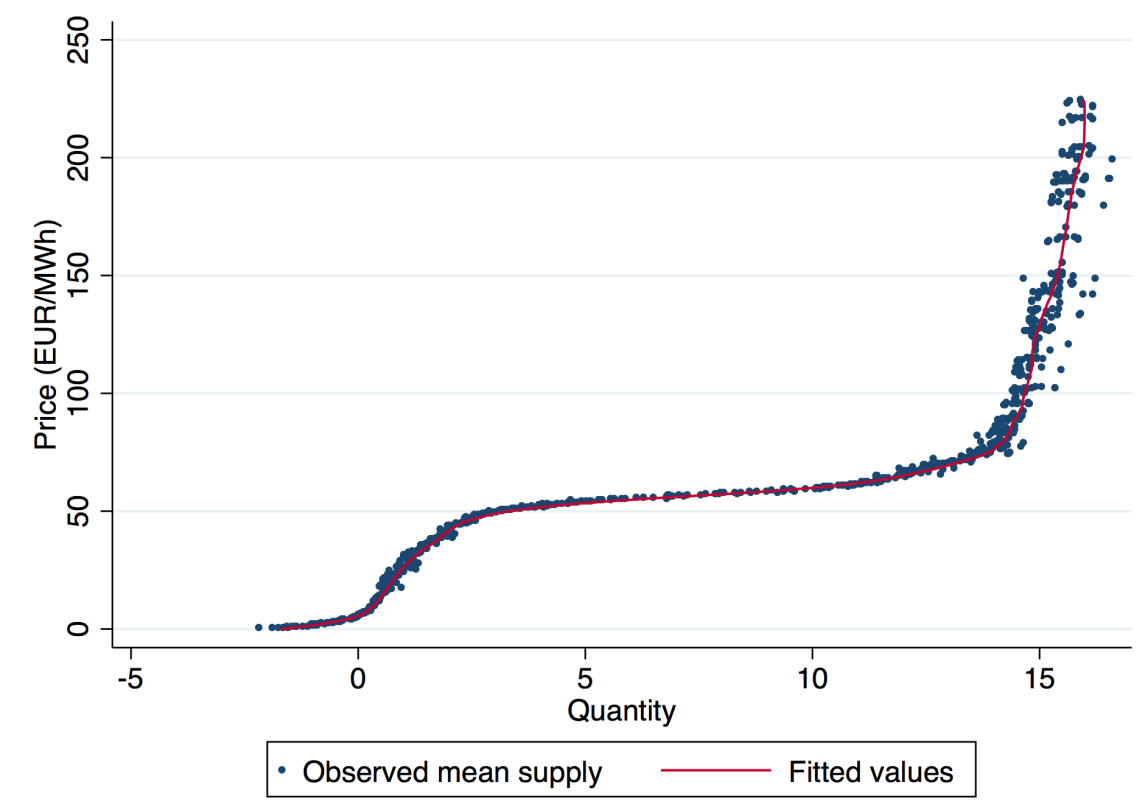

Note: The figure shows a representative residual supply function in the Nordic market during one week, including the raw data consisting of each bid during that same week (excluding Cournot bids). 
Figure 4: Observed vs predicted prices using representative weekly supply functions

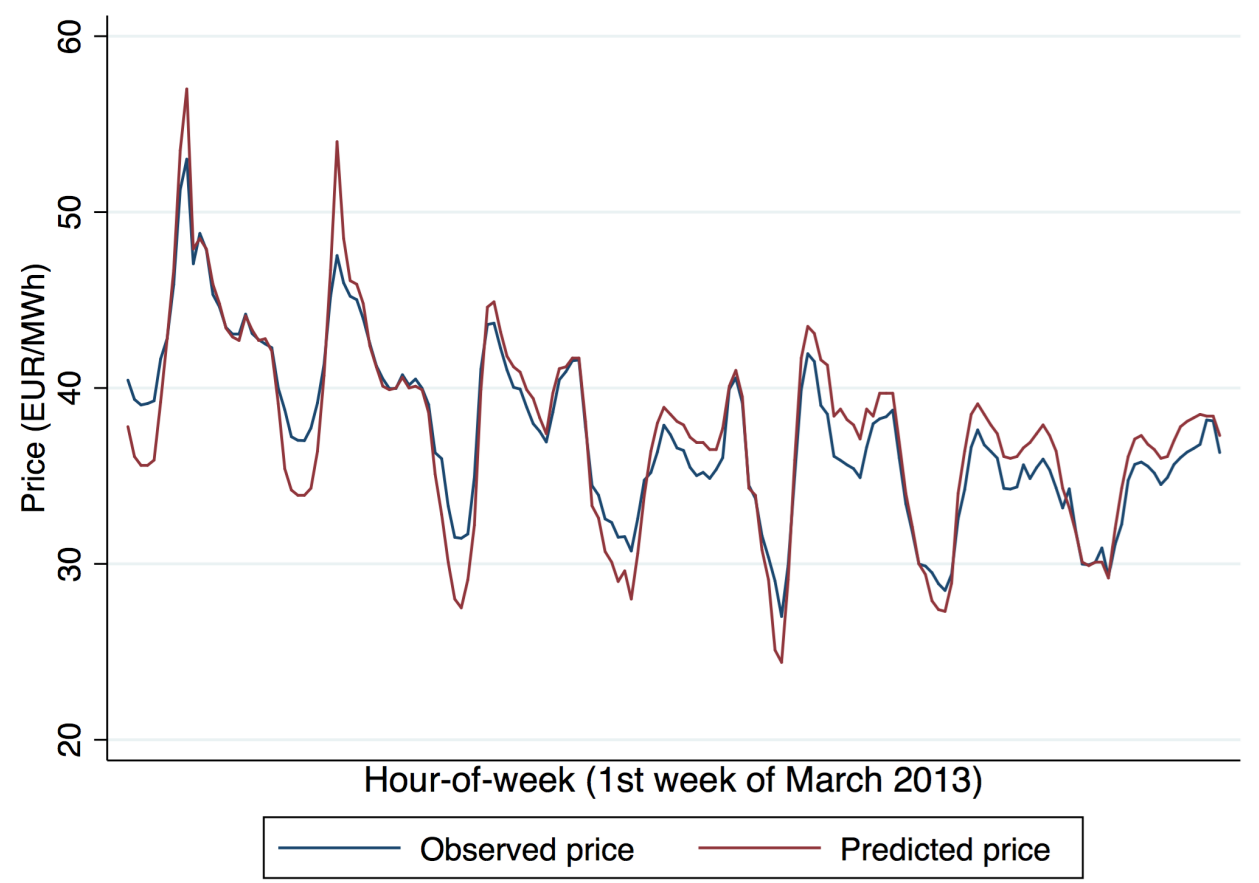

Note: This figure depicts observed vs. predicted prices in the Nordic day-ahead market during March 2013. When determining the predicted prices, within-week variation in the supply bids comes from inelastic Cournot bids only.

output with low marginal cost, i.e. wind and run-of-the-river hydro plants (solar output is negligible in the Nordic region). But intermittent output can only account for a fraction of the supply shifts, and wind only five percent of total Nordic output during the sample period.

There are several reasons why a strategic firm would bid its production inelastically into the market instead of applying more complex bidding strategies. First, it could be in all firms' joint best-interest if everybody places price-inelastic bids. This reduces the price-elasticity of all firms' residual demand curves and drives up the equilibrium price. If, in addition, there is little demand uncertainty at the bidding stage, it is a unilaterally profit maximizing strategy to submit a price inelastic bid. Coordinating on price-inelastic bids then is a sustainable equilibrium. Second, a price-dependent bid curve represents a benchmark of the marginal cost curve against which a market monitor can evaluate a firm that claims to behave competitively. On the contrary, outside observers cannot draw any direct conclusions about marginal costs based upon a price inelastic bid. Third, technical constraints create incentives to submit low bids to to ensure that production does not have to adjust across hours. The Nordic market design is of a uniform marginal price that does not allow firms separate recovery of startup costs. Firms can partly use block bids to that effect, but these only accounted for six percent of the accepted bids during the sample period. Hence, we conclude that the Cournot bids should contain a substantial amount of information about firms' strategic choices. 


\subsection{Estimation}

In light of Proposition 1, we want to estimate

$$
Q_{t}=\beta_{0}+\beta_{1} p_{t}+\beta_{2}\left|P_{Q}^{t}\right|+\beta_{3} X_{t}^{S}+\beta_{4} X_{t}^{D}+v_{t}+\varepsilon_{t},
$$

where index $t$ refers to the sample hour. The $\beta_{1}$ estimate measures the effect of an increase in the price, and $\beta_{2}$ measures the market power effect on Cournot output. The vectors $X_{t}^{S}$ and $X_{t}^{D}$ are exogenous supply and demand controls, and $v_{t}$ is a vector of time fixed effects. $\varepsilon_{t}$ is the econometric error term, capturing both optimization errors and unobserved supply shocks, such as plant failures. To allow for serial correlation in the error term, we cluster standard errors by sample week.

Fixed effects As electricity consumption is cyclical, we acknowledge that each observation $t$ belongs to a certain hour of the day $h$, day $d$, sample week $w$ and sample month $m$. In the main specification, we therefore add fixed effects for each hour-of-the-day, a weekend dummy, and sample week fixed effects. Conveniently, the quantity of financial forward contracts remains essentially constant within each sample week. Hence, the sample week fixed effects ensure that no identifying source of variation comes from forward contracts. Also, fuel and $\mathrm{CO}_{2}$ prices only vary trivially within each week. As a robustness test, we also estimate the model substituting the sample week fixed effects with a vector of sample day and sample month fixed effects.

Controls In the demand and supply controls, we add wind output and temperature. A large share of Nordic electricity consumption is used for heating, so temperature is an important determinant of demand. However, temperature changes also affect the opportunity cost of hydro power production, since high temperatures melt ice and snow that flow into the reservoirs (although the demand effect is likely to dominate the supply effect). Within Sweden, the other determinant of reservoir inflow, precipitation, is also correlated with temperature (Cong and Brady, 2012). Wind is mainly a supply shifter, but could also increase the need for heating. In the specification where we include sample month fixed effects, we are also able to control for hydro inflow directly, since data on hydro inflow is available on a weekly basis.

Instruments The model cannot be estimated using OLS, due to reverse causality. Contracting Cournot output will always have a positive effect on the price independent of the shape of the residual demand function. When the residual demand function is convex, there is also a positive effect on the (absolute) slope, while the opposite is true when the residual demand function is concave. Since Proposition 1 shows that the marginal effect of an increase in the demand shifter $\sigma$ is additively separable in price and slope, it is convenient to use demand shifters as instruments. Since we have two endogenous variables, we need two instruments that are not perfectly correlated, $\sigma_{1}$ and $\sigma_{2}$. We use forecasted demand and its square. Forecasted demand has previously been used as an instrument for price by e.g. Kim and Knittel (2006). The demand forecast does not take price into account. It is determined by indicators of weather and economic activity, and thus satisfies the exogeneity assumption. Forecasted demand is a 
very strong determinant of the actual quantity cleared in the spot market, with a within-year correlation of above 0.95 , confirming that the short run price elasticity of demand is very low. By definition, the IV-coefficients associated with (7) are then

$$
\frac{1}{\beta_{1}^{I V}}=\frac{d P / d \sigma_{1}}{d Q / d \sigma_{1}}+\frac{d P / d \sigma_{2}}{d Q / d \sigma_{2}}, \frac{1}{\beta_{2}^{I V}}=\frac{d P_{Q} / d \sigma_{1}}{d Q / d \sigma_{1}}+\frac{d P_{Q} / d \sigma_{2}}{d Q / d \sigma_{2}}
$$

Convexity of the residual demand function. When the market clears on the convex part of the residual demand function, the price effect of a withdrawal is larger than when the market clears on the concave part, influencing the incentives to exert market power. Figure B.3 depicts the mean curvature (i.e. $P_{Q Q}$ ) and the slope of the residual demand function depending on hour-of-the-day for all observations in the sample. Between 7 am and $11 \mathrm{pm}$ when demand is high, the residual demand function is usually convex (i.e. the second derivative is positive), while the opposite is true for the remaining hours. It is also likely that technical constraints are different during high- vs low demand. During high demand, most units are running, and capacity constraints and ramping costs account for most of the variation in marginal costs. Transmission constraints also bind more often when demand is high, enhancing the ability to influence the price within a given price area. Also, when firms are producing closer to their capacity constraints, the chance of being a pivotal supplier increases.

During low demand hours when only base load plants are operating, marginal costs depend on startup costs and lower production constraints. For example, hydro power owners have to take into consideration lower production constraints due to environmental regulations, and the fact that turbines do not operate efficiently if capacity utilization is too low. Therefore, we also test if the response to the slope is greater when the market clears on the convex part of the residual demand function. Further, since the correlation between forecasted demand and the (absolute) slope is positive when residual demand is convex (0.23), and negative when residual demand is concave (-0.08), the distinction is also relevant from an econometric perspective in the first-stage regression.

\subsection{Results}

The regression results are presented in Table 4 with the IV-coefficients in the top part of the table. The Cragg-Donald F-statistics remains high throughout all specifications, confirming that instruments are strong. In column (1), we estimate the model without controls, and add controls in column (2). The magnitudes of the effects are only trivially affected, but the precision is increased when including the controls. All coefficients are of the expected sign in column (2) and statistically significant. A steeper slope leads to a contraction of Cournot output, consistent with the notion that producers exert market power. A higher price is associated with an expansion of Cournot output. Higher wind output expands Cournot output, which could be explained by a reduction in marginal production costs. Higher temperatures reduce demand, which in turn contracts Cournot output. We estimate in columns (3) and (4) the model on the sample 
Table 4: Results from the main specification

\begin{tabular}{lcccccc}
\hline & $(1)$ & $(2)$ & $(3)$ & $(4)$ & $(5)$ & $(6)$ \\
\hline Slope & -0.20 & $-0.27 * *$ & $-0.30 * *$ & -0.23 & $-0.28 * * *$ & $-0.23 *$ \\
& $(0.130)$ & $(0.126)$ & $(0.130)$ & $(0.183)$ & $(0.102)$ & $(0.127)$ \\
Price & $0.071 * * *$ & $0.065 * * *$ & $0.081 * * *$ & $0.058 * * *$ & $0.056 * * *$ & $0.070 * * *$ \\
& $(0.0217)$ & $(0.0214)$ & $(0.0248)$ & $(0.0215)$ & $(0.0195)$ & $(0.0214)$ \\
Wind output & & $0.94 * * *$ & $0.90 * * *$ & $0.96 * * *$ & $0.76 * * *$ & $1.16 * * *$ \\
& & $(0.0783)$ & $(0.0808)$ & $(0.0870)$ & $(0.0738)$ & $(0.103)$ \\
Temperature & & $-0.043 * * *$ & $-0.041 * * *$ & $-0.046 * * *$ & $0.035 * *$ & $-0.078 * * *$ \\
& & $(0.0149)$ & $(0.0154)$ & $(0.0161)$ & $(0.0179)$ & $(0.0164)$ \\
Reservoir inflow & & & & & 1.01 \\
& & & & & & $(1.041)$ \\
\hline Median markup (percent) & 7.02 & 10.6 & 9.13 & 9.77 & 12.2 & 8.31 \\
Fixed effect & Week & Week & Week & Week & Day & Month \\
Sample & Full & Full & Convex & Concave & Full & Full \\
Cragg-Donald F-stat & 30.2 & 33.2 & 29.0 & 24.0 & 38.1 & 32.0 \\
N & 25091 & 25091 & 13043 & 12048 & 25091 & 25091
\end{tabular}

Note: The dependent variable is the Cournot quantity. Hour-of-day and weekend fixed effects are included in all regressions. The price and the slope are instrumented using forecasted demand and its square. Standard errors are clustered by sampleweek.

hours where the market clears on the convex respective concave portion of the residual demand curve. This division essentially represents a partition of the sample into peak versus off-peak hours. Both subsamples comprise about half the observations each. The slope coefficient has the same magnitude in both regressions, but is only significant in column (3), suggesting that the exercise of market power is more systematic in peak hours than off-peak hours. Including daily fixed effects in column (5) or monthly fixed effects in column (6) does not affect the slope coefficient much, but the temperature estimate switches sign in the specification with daily fixed effects.

For comparison, we present the corresponding OLS estimates in Table B.1. The price coefficient now is negative, indicating the presence of reverse causality, and the sign of the slope coefficient is also reversed. However, the coefficients on the exogenous variables, wind output and temperature, have the same signs as in the IV-estimates, as expected.

Interpretation and discussion The negative slope estimates in Table 4 are consistent with firms exercising market power by withholding more production from the day-ahead market when day-ahead prices are more sensitive to reductions in output. Are those estimates inconsistent with outcomes that would arise under perfect competition? To explore this issue, assume for the sake of exposition that demand is additively separable in the wholesale price $\hat{p}$ and the demand parameter $\sigma, X(\hat{p}, \sigma)=\sigma+S(\hat{p})$, and price inelastic, $\left|S^{\prime}(\hat{p})\right|$ is small. Suppose the market is indeed perfectly competitive, so that even the $k$ firms with market power supply power at 
marginal cost. Based upon the theoretical analysis in Section 2, we get the following marginal effects of an exogenous increase in demand

$$
Q_{\sigma}=P_{\sigma} H>0 \text { and } P_{Q \sigma} \approx-M C_{q q}^{r}
$$

In the relevant case of the competitive fringe having convex marginal costs, an increase in demand would be associated with a larger Cournot quantity $Q$ and a larger value of $\left|P_{Q}\right|$ under perfect competition, in which case the estimate $\beta_{2}$ in specification (4) of Table 4 would have been (weakly) positive instead of significantly negative. Hence, we reject the hypothesis that Nord Pool was perfectly competitive during the sample period.

The above demand specification illustrates how our method differs from Bresnahan-Lau. That model relies upon the existence of exogenous variables that rotate demand around the price. Such rotation does not exist here by the assumption that $X_{\sigma p}=0$. Instead, all changes in demand occur as horizontal shifts in the residual demand curve, such as those illustrated in Figure 2. The lack of slope rotation can pose a serious obstacle to the applicability of the Bresnahan-Lau model in wholesale electricity markets and therefore render alternative methods, such as the one we develop in this paper, useful.

The curvature of the residual demand also shows why it is convenient to regress the slope $\left|P_{Q}\right|$ on the Cournot quantity $Q$ instead of the price $p$. Suppose, on the contrary, we estimated

$$
p_{t}=\hat{\beta}_{0}+\hat{\beta}_{1}\left|P_{Q}^{t}\right|+\hat{\beta}_{2} X_{t}^{S}+\hat{\beta}_{3} X_{t}^{D}+\hat{v}_{t}+\hat{\varepsilon}_{t}
$$

based on equilibrium condition (3). A positive and significant estimate $\hat{\beta}_{1}$ would be consistent with firms exercising market power. But the price $p$ and the slope $\left|P_{Q}\right|$ tend to be positively correlated even under perfect competition if the marginal cost function of the residual fringe is convex. In this case, $\hat{\beta}_{1}>0$ would also be consistent with perfect competition. Using price as the dependent variable would not permit us to identify market power during peak hours, which is exactly when such problems would most likely occur.

Having interpreted the sign of the slope coefficients in Table 4, the next question is how to interpret the magnitude of the coefficients. To do so, we add more structure to the theoretical model. Recall from Section 2 that we could obtain an equilibrium condition with the total Cournot quantity $Q$ on the left hand side by assuming that each of the $k$ firms with market power had linear marginal cost functions $M C^{i}=\gamma_{i}+c_{i} \tilde{q}_{i}$. By imposing symmetry across the $k$ firms equilibrium condition (4) simplifies to

$$
Q=-k \frac{\gamma}{c}+p \frac{k}{c}-\left|P_{Q}\right| k \alpha \frac{q-f}{c} .
$$

Subject to the independent variables in (7) having been properly instrumented, $\beta_{1}=\frac{k}{c}$ and 
$\beta_{2}=-k \alpha \frac{q-f}{c}$, in which case

$$
-\frac{\beta_{2}}{\beta_{1}} \frac{\left|P_{Q}\right|}{p}=\alpha(q-f) \frac{\left|P_{Q}\right|}{p}=\frac{p-m c}{p}
$$

where the second equality follows from imposing symmetry on (2).

Our model delivers in the parametric case a structural estimate of market performance, instead of being a purely diagnostic test of whether the market is competitive. We present the implied markups in Table 4 . These are median rather than mean markups because the slope variable is skewed to the right due to a few observations with very steep residual demand curves. Median markups are roughly the same across the specifications (1)-(4) based on weekly fixed effects and are in the range 7 to 10.6 percent. Specification (6), which relies on monthly fixed effects, produces a similar result. Including daily fixed effects in column (5) yields a somewhat higher estimated markup, at 12.2 percent.

Did firms exercise more market power after the introduction of price areas? November 1, 2011, Sweden was divided into four price areas on Nord Pool. Previously, the day-ahead price had been the same all across Sweden, even when domestic transmission constraints implied local imbalances of supply and demand at the computed market price. The creation of price areas was done to reduce local imbalances in the electricity system. ${ }^{6}$ Introducing price areas does not physically alter the market, but can have indirect consequences for market performance, for instance by affecting producers' incentives to vertically integrate into the retail market or to change their forward contract coverage (Tangerås and Wolak, 2017). As Sweden supplies around 40 percent of the electricity sold on Nord Pool, a behavioral change among the producers in the country should be detectable also in the aggregate data. The geographical borders of the prize areas are depicted in Figure B.4.

To test the extent to which the introduction of price areas affected competition, we estimate the main specification on the data both before and after the reform. The identifying assumption of this test is that no other important changes took place around this time. We do not know of any other such events. Table 5 depicts the results. For the sample preceding the reform, the slope coefficient is positive, which translates into a negative measure of the markup. However, the Cragg-Donald F-statistic is below 10, indicating that instruments are weak and thus that the estimates may be very biased. For the sample following the reform, instruments are instead strong, and the implied markup is now 14 percent, i.e. somewhat higher than when including the whole sample. These results give some support to the hypothesis that the reform lead to less competitive behavior in the day-ahead market.

\footnotetext{
${ }^{6}$ Historically, the Swedish Transmission System Operator, SvK, had ensured local market clearance across Sweden either by means of a complementary counter-trade mechanism or by reducing trade with neighboring countries. This second policy of "moving congestion to the border" was viewed by the EU competition authority to constitute a potential abuse of dominant position by SvK. Hence, the introduction of price areas,
} 
Table 5: Effect of introducing prize areas

\begin{tabular}{lcc}
\hline & Before & After \\
\hline Slope & $0.43 * *$ & $-0.50 * * *$ \\
& $(0.2)$ & $(0.2)$ \\
Price & $0.074 * * *$ & $0.093 * * *$ \\
& $(0.02)$ & $(0.03)$ \\
Wind output & $0.80 * * *$ & $0.92 * * *$ \\
& $(0.2)$ & $(0.08)$ \\
Temperature & $-0.085 * * *$ & -0.0069 \\
& $(0.02)$ & $(0.02)$ \\
\hline Median markup (percent) & -14.4 & 13.6 \\
Fixed effect & Week & Week \\
Cragg-Donald F-stat & 7.45 & 33.4 \\
N & 7666 & 17425 \\
\hline
\end{tabular}

Note: The dependent variable is the Cournot quantity. The price and the slope are instrumented using forecasted consumption and its square. Hour-of-day, week-of-sample, and weekend fixed effects are included in both estimates. Sweden was divided into four price areas on November 1, 2011.

\section{Conclusion}

We have theoretically analyzed electricity wholesale markets characterized by Cournot competition and used these results to formulate an empirical test to evaluate the exercise of market power on the basis of aggregate bid data. We have applied the method to the Nordic electricity market and estimated markups between 8 and 11 percent during our sample period 2011-2013. We also find some support for the hypothesis that the price reform of 2011 lead to more anti-competitive behavior. The method can be used in order to evaluate market power also in other wholesale markets where only aggregate bidding data is available, insofar as strategic interaction can be appropriately described in terms of Cournot competition. ${ }^{7}$

We have only been able to test the model on aggregate data for the Nordic market. One might expect local variations in supply conditions and market concentration to yield also local variations in competition depending on country and price area. To increase the precision of future empirical analyses of market performance in the Nordic market, we strongly recommend Nord Pool to disclose bid and supply data at least at price area level.

\footnotetext{
${ }^{7}$ An obvious candidate for analysis would be the European Power Exchange EPEX.
} 


\section{References}

Bask, Mikael, Jens Lundgren, and Nilkas Rudholm, "Market power in the expanding Nordic power market," Applied Economics, 2011, 43 (9), 1035-1043.

Bresnahan, Timothy F., "The oligopoly solution concept is identified," Economics Letters, 1982, 10 (1-2), 87-92.

Bushnell, James B., Erin T. Mansur, and Celeste Saravia, "Vertical arrangements, market structure, and competition: An analysis of restructured US electricity markets," American Economic Review, March 2008, 98 (1), 237-66.

Cong, Rong-Gang and Mark Brady, "The interdependence between rainfall and temperature: Copula analyses," The Scientific World Journal, 2012, 2012, 11.

Damsgaard, Niklas, "Market power in the Nordic power market," Working Paper Series 2007003, Econ Pöyry 2007.

Dixit, Avinash, "Comparative statics for oligopoly," International Economic Review, 1986, 27 (1), 107-22.

Fabra, Natalia and Juan Toro, "Price wars and collusion in the Spanish electricity market," International Journal of Industrial Organization, April 2005, 23 (3-4), 155-181.

Fogelberg, Sara and Ewa Lazarczyk, "Strategic withholding through production failures," Working Paper Series 1015, Research Institute of Industrial Economics March 2014.

Green, Richard J and David M Newbery, "Competition in the British electricity spot market," Journal of Political Economy, October 1992, 100 (5), 929-53.

Hortaçsu, Ali and Steven L. Puller, "Understanding strategic bidding in multi-unit auctions: a case study of the Texas electricity spot market," RAND Journal of Economics, 2008, 39 (1), $86-114$.

Ito, Koichiro and Mar Reguant, "Sequential markets, market power, and arbitrage," American Economic Review, July 2016, 106 (7), 1921-57.

Kauppi, Olli and Matti Liski, "An empirical model of imperfect dynamic competition and application to hydroelectricity storage," Working Papers, Massachusetts Institute of Technology, Center for Energy and Environmental Policy Research 2008.

Kim, Dae-Wook and Christopher R. Knittel, "Biases in static oligopoly models? Evidence from the California electricity market," Journal of Industrial Economics, December 2006, 54 (4), 451-470.

Lau, Lawrence J., "On identifying the degree of competitiveness from industry price and output data," Economics Letters, 1982, 10 (1-2), 93-99. 
Lundin, Erik, "Market power and joint ownership: Evidence from nuclear plants in Sweden," Working Paper Series 1113, Research Institute of Industrial Economics February 2016.

McRae, Shaun D. and Frank A. Wolak, "How do firms exercise unilateral market power? Empirical evidence from a bid-based wholesale electricity market," in Eric Brousseau and Jean-Michel Glachant, eds., The Manufacturing of Markets, Cambridge University Press, 2014, pp. 390-420. Cambridge Books Online.

Mercadal, Ignacia, "Dynamic competition and arbitrage in electricity markets: The role of financial players," Working Paper, MIT Sloan School of Management 2016.

Nordreg, "Methods for evaluation of the Nordic forward market for electricity market for electricity," Report Consultance report by EC group, Nordic Energy Regulators 2016.

Sweeting, Andrew, "Market power in the England and Wales wholesale electricity market 1995-2000," Economic Journal, 04 2007, 117 (520), 654-685.

Tangerås, Thomas P. and Frank A. Wolak, "The competitive effects of linking electricity markets across space and time," Working Paper 1184, Research Institute of Industrial Economics May 2017.

- and Johannes Mauritzen, "Real-time versus day-ahead market power in a hydro-based electricity market," Discussion Papers 2014/6, Department of Business and Management Science, Norwegian School of Economics February 2017.

Willems, Bert, Ina Rumiantseva, and Hannes Weigt, "Cournot versus supply functions: What does the data tell us?," Energy Economics, January 2009, 31 (1), 38-47.

Wolak, Frank A., "Measuring unilateral market power in wholesale electricity markets: The California market, 1998-2000," American Economic Review, 2003, 93 (2), 425-430.

_, "Quantifying the supply-side benefits from forward contracting in wholesale electricity markets," Journal of Applied Econometrics, 2007, 22 (7), 1179-1209.

- and Robert H. Patrick, "The impact of market rules and market structure on the price determination process in the England and Wales electricity market," Working Paper 8248, National Bureau of Economic Research April 2001.

Wolfram, Catherine D., "Measuring duopoly power in the British electricity spot market," American Economic Review, 1999, 89 (4), 805-826. 


\section{Appendix A: Proof of Proposition 1}

A total differentiation of the $k$ equilibrium conditions

$$
P\left(Q, \sigma, \gamma_{r}\right)-M C^{i}\left(q_{i}, \gamma_{i}\right)+\alpha_{i}\left(q_{i}-f_{i}\right) P_{Q}\left(Q, \sigma, \gamma_{r}\right)=0
$$

yields $\mathbf{A d q}=\mathbf{b} d \sigma$, where $\mathbf{A}$ is a $k \times k$ symmetric matrix with diagonal element $i$ equal to

$$
1+a_{i}=1+\frac{\alpha_{i} P_{Q}-M C_{q}^{i}}{P_{Q}+\alpha_{i}\left(q_{i}-f_{i}\right) P_{Q Q}}
$$

and all off-diagonal elements equal to 1 , $\mathbf{d q}=\left(d q_{1}, \cdots, d q_{i}, \cdots, d q_{k}\right)^{\prime}$, and $\mathbf{b}$ is a $k \times 1$ vector with element $i$ equal to

$$
b_{i}=-\frac{P_{\sigma}+\alpha_{i}\left(q_{i}-f_{i}\right) P_{Q \sigma}}{P_{Q}+\alpha_{i}\left(q_{i}-f_{i}\right) P_{Q Q}}
$$

To evaluate the determinant $|\mathbf{A}|$, subtract the last column in $\mathbf{A}$ from each of the other $k-1$ columns, multiply the resulting matrix by $\left(\frac{a_{k}}{a_{1}}, \cdots, \frac{a_{k}}{a_{i}}, \cdots, \frac{a_{k}}{a_{k-1}}, 1\right)^{\prime}$ and add all the first $k-1$ rows to row $k$ to obtain a triangular matrix with diagonal element $k$ equal to $a_{k}\left(1+\sum_{j=1}^{k} \frac{1}{a_{j}}\right)$ and all other diagonal elements equal to $a_{k}$. We can then solve for

$$
|\mathbf{A}|=\prod_{j=1}^{k} a_{j}\left(1+\sum_{j=1}^{k} \frac{1}{a_{j}}\right) .
$$

To find the effect of $d \sigma$ on $d q_{i}$, we must find also the determinant $\left|\mathbf{A}_{i}\right|$ of the matrix $\mathbf{A}_{i}$ resulting from substituting $\mathbf{b}$ for column $i$ in $\mathbf{A}$. Subtract the last column in $\mathbf{A}_{i}$ from each of the other $k-1$ columns, multiply the resulting matrix by $\left(\frac{a_{k}}{a_{1}}, \cdots, 1, \cdots, \frac{a_{k}}{a_{k-1}}, 1\right)^{\prime}$ and add all $k-1$ rows except $i$ to the last row to get

$$
\left(\begin{array}{cccccccc}
a_{k} & 0 & \cdots & \frac{a_{k}}{a_{1}}\left(b_{1}-1\right) & \cdots & 0 & 0 & \frac{a_{k}}{a_{1}} \\
\vdots & \vdots & \ddots & \vdots & \vdots & \vdots & \vdots & \vdots \\
0 & 0 & \cdots & b_{i}-1 & \cdots & 0 & 0 & 1 \\
\vdots & \vdots & \vdots & \vdots & \ddots & \vdots & \vdots & \vdots \\
0 & 0 & \cdots & \frac{a_{k}}{a_{k-1}}\left(b_{k-1}-1\right) & \cdots & 0 & a_{k} & \frac{a_{k}}{a_{k-1}} \\
0 & 0 & \cdots & a_{k}\left(\sum_{j \neq i}^{k} \frac{b_{j}-1}{a_{j}}-1\right) & \cdots & 0 & 0 & a_{k}\left(1+\sum_{j \neq i}^{k} \frac{1}{a_{j}}\right)
\end{array}\right)
$$


Multiply this matrix by $\left(1, \cdots, 1, \frac{a_{i+1}}{a_{k}} \frac{1-b_{i}}{b_{i+1}-1}, \cdots, \frac{a_{k-1}}{a_{k}} \frac{1-b_{i}}{b_{k-1}-1}, \frac{1-b_{i}}{a_{k}\left(\sum_{j \neq i}^{k} \frac{b_{j}-1}{a_{j}}-1\right)}\right)^{\prime}$ and add row $i$ to each of the last $k-i$ rows to get the triangular matrix

$$
\left(\begin{array}{cccccccc}
a_{k} & 0 & \cdots & \frac{a_{k}}{a_{1}}\left(b_{1}-1\right) & \cdots & 0 & 0 & \frac{a_{k}}{a_{1}} \\
\vdots & \vdots & \ddots & \vdots & \vdots & \vdots & \vdots & \vdots \\
0 & 0 & \cdots & b_{i}-1 & \cdots & 0 & 0 & 1 \\
\vdots & \vdots & \vdots & \vdots & \ddots & \vdots & \vdots & \vdots \\
0 & 0 & \cdots & 0 & \cdots & 0 & a_{k-1} \frac{1-b_{i}}{b_{k-1}-1} & \frac{1-b_{i}}{b_{k-1}-1}+1 \\
0 & 0 & \cdots & 0 & \cdots & 0 & 0 & \left(1-b_{i}\right) \frac{1+\sum_{j \neq i}^{k} \frac{1}{a_{j}}}{\sum_{j \neq i}^{k} \frac{b_{j}-1}{a_{j}}-1}+1
\end{array}\right)
$$

We are now in a position to solve:

$$
\left|\mathbf{A}_{i}\right|=\left[\frac{b_{i}}{a_{i}}+\sum_{j=1}^{k} \frac{b_{i}-b_{j}}{a_{i} a_{j}}\right] \prod_{j=1}^{k} a_{j} .
$$

By Cramer's rule, $\frac{\partial q_{i}}{\partial \sigma}=\frac{\left|\mathbf{A}_{i}\right|}{|\mathbf{A}|}$. Hence,

$$
Q_{\sigma}=\sum_{i=1}^{k} \frac{\partial q_{i}}{\partial \sigma}=\sum_{i=1}^{k} \frac{\left|\mathbf{A}_{i}\right|}{|\mathbf{A}|}=\frac{\sum_{i=1}^{k} \frac{b_{i}}{a_{i}}+\sum_{i=1}^{k} \sum_{j=1}^{k} \frac{b_{i}-b_{j}}{a_{i} a_{j}}}{1+\sum_{j=1}^{k} \frac{1}{a_{j}}}=\frac{\sum_{i=1}^{k} \frac{b_{i}}{a_{i}}}{1+\sum_{i=1}^{k} \frac{1}{a_{i}}}
$$

Substituting the expressions for $a_{i}$ and $b_{i}$ into $Q_{\sigma}$ above produces (5) and (6).

A particular Cournot equilibrium is stable only if (Dixit, 1986):

$$
(-1)^{k} \prod_{i=1}^{k}\left[\alpha_{i} P_{Q}-M C_{q}^{i}\right]\left[1-\sum_{i=1}^{k} \frac{P_{Q}+\alpha_{i}\left(q_{i}-f_{i}\right) P_{Q Q}}{M C_{q}^{i}-\alpha_{i} P_{Q}}\right]>0 .
$$

By $\alpha_{i} P_{Q}<M C_{q}^{i}$, this condition is equivalent to the denominator of $H$ defined in (6) being strictly positive. The numerator of $H$ is strictly positive. Hence, $H>0$ in stable equilibrium. 


\section{Appendix B}

Figure B.1: Horizontal supply shifts in Germany

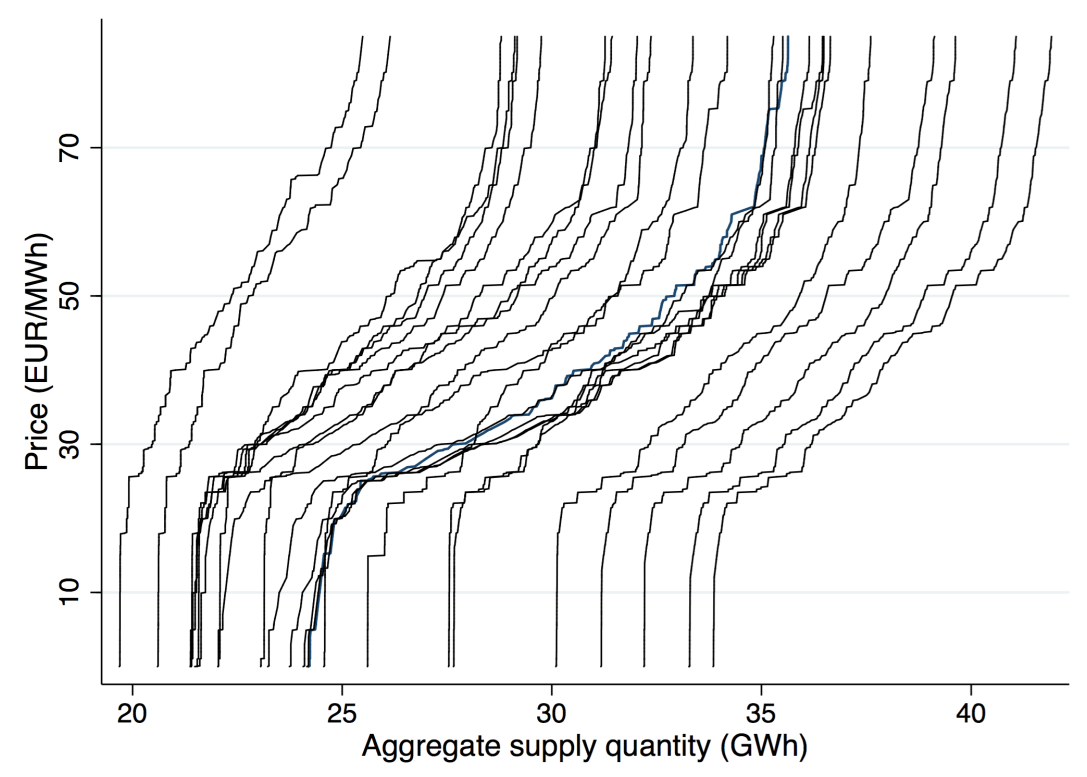

Note: This figure depicts aggregate supply bids in the German bidding area day-ahead market (EPEX) during one day.

Figure B.2: Horizontal supply shifts in MISO

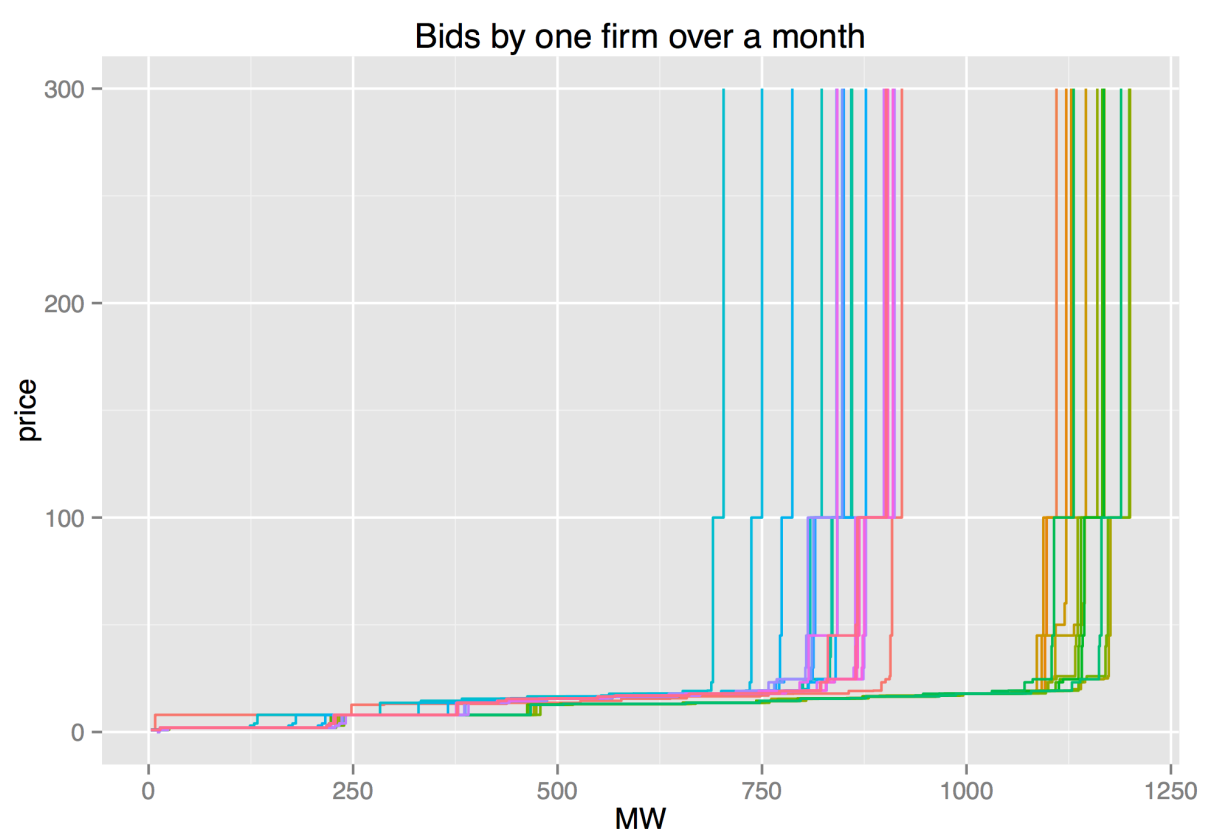

Note: Supply bids for one firm over one month in MISO. Source: Mercadal (2016). 
Figure B.3: Slope and curvature depending on hour-of-the-day

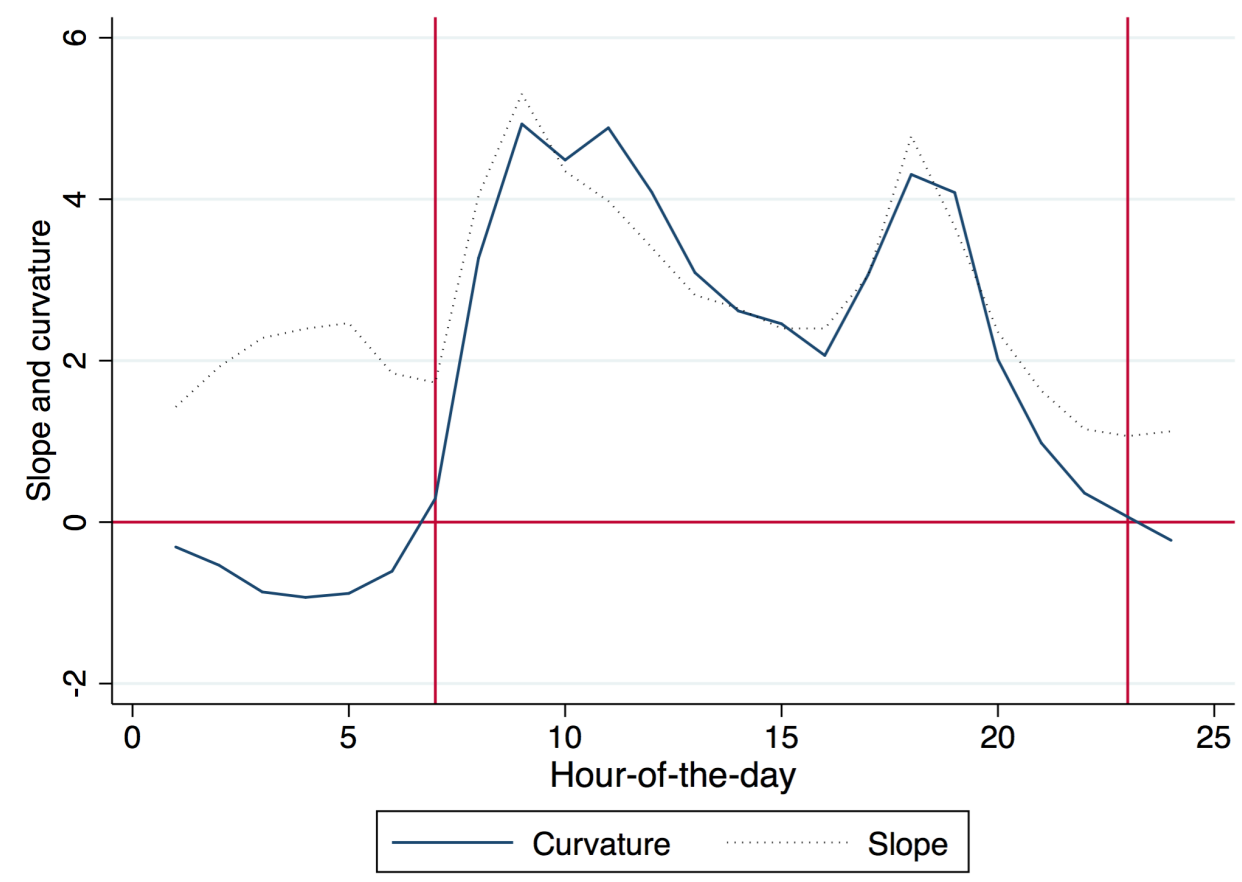

Note: This figure shows the mean equilibrium (absolute) slope and curvature, depending on hour-of-the-day.

Figure B.4: Price areas after Nov 12011

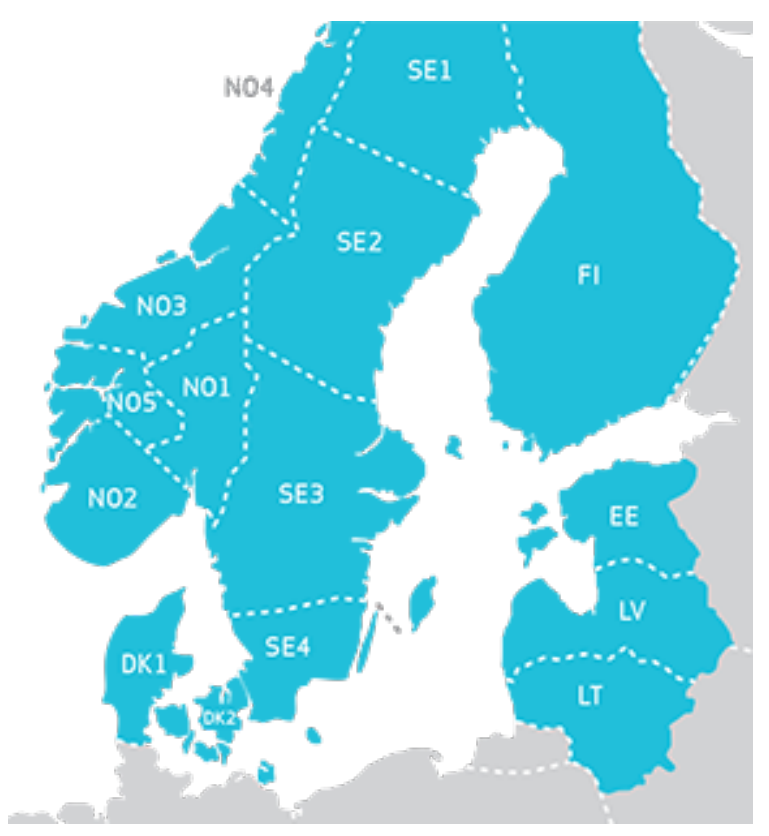

Note: Geographical borders of the price areas in the Nordic region after November 12011. 
Table B.1: Main specification, OLS results

\begin{tabular}{lc}
\hline & $(\mathrm{OLS})$ \\
\hline Slope & $0.037 * * *$ \\
& $(0.012)$ \\
Price & $-0.12 * * *$ \\
& $(0.014)$ \\
Wind output & $0.66 * * *$ \\
& $(0.064)$ \\
Temperature & $-0.068 * * *$ \\
& $(0.013)$
\end{tabular}

Reservoir inflow

$\begin{array}{lc}\text { Median markup (percent) } & 0.79 \\ \text { Fixed effect } & \text { Week } \\ \text { Sample } & \text { Full } \\ \text { Cragg-Donald F-stat } & \\ \text { N } & 25091\end{array}$

Note: The dependent variable is the Cournot quantity. Hour-of-day and weekend fixed effects are included in all regressions. Standard errors are clustered by sample week. 